\title{
Airway surgery in children under extracorporeal circulatory support
}

\author{
Arun Beeman ${ }^{1}$, Madhavan Ramaswamy $^{1}$, Alex Robertson ${ }^{2}$, James Ip $^{3}$, Nagarajan Muthialu ${ }^{1}$ \\ ${ }^{1}$ Paediatric Cardiothoracic and Tracheal Surgery, Great Ormond Street Children Hospital, NHS Trust, London, UK; ${ }^{2}$ Great Ormond Street \\ Children Hospital, NHS trust, London, UK; ${ }^{3}$ Cardiac Department, Great Ormond Street Children Hospital, NHS trust, London, UK \\ Contributions: (I) Conception and design: All authors; (II) Administrative support: None; (III) Provision of study materials or patients: None; (IV) \\ Collection and assembly of data: None; (V) Data analysis and interpretation: None; (VI) Manuscript writing: All authors; (VII) Final approval of \\ manuscript: All authors. \\ Correspondence to: Mr. Nagarajan Muthialu, FRCSEd. Consultant Cardiothoracic Surgeon, lead Thoracic and Tracheal surgeon, Great Ormond \\ Street Hospital for Children, Great Ormond Street, London WC1N 3JH, UK. Email: Nagarajan.Muthialu@gosh.nhs.uk.
}

\begin{abstract}
Airway surgery can be challenging in children. With increasing awareness of congenital lesions, expertise in diagnostic modalities and recent advances in surgical technique, complex airway malformations are increasingly better managed. Physiological and anatomical differences, combined with specific features of surgical problems seen in childhood, necessitate a different approach to perioperative care compared with adults. An often essential component for efficient and complete surgical correction is the appropriate utilisation of extracorporeal circulatory support. This article details the key differences between the paediatric and adult patient with respect to airway surgery, before discussing the role and applications of extracorporeal circulatory support in various airway reconstructions in children. We discuss the potential alternate options including use of extra-corporeal membrane oxygenation versus standard cardiopulmonary bypass $(\mathrm{CPB})$ during surgery.
\end{abstract}

Keywords: Airway surgery; cardiopulmonary bypass (CPB); tracheal reconstruction

Received: 12 January 2021. Accepted: 12 March 2021.

doi: $10.21037 /$ ccts-21-9

View this article at: http://dx.doi.org/10.21037/ccts-21-9

\section{Introduction}

Airway surgery in paediatric patients presents distinct challenges compared with the adult population due to significant differences in cardiorespiratory physiology and anatomy. These differences also predispose neonates and infants to an increased risk of perioperative complications. The cardiovascular and respiratory systems undergo extensive changes from foetal life to later childhood; these changes, combined with the technical challenges of surgery, render younger patients more vulnerable to cardiorespiratory insufficiency during airway surgery. This disparity between adult and infant patients means that extracorporeal circulatory support is rarely required in adult airway surgery; however, in paediatric patients it has become an essential component of safe and effective perioperative management.

\section{Unique characteristics of paediatric airway physiology and anatomy}

Several notable characteristics of the paediatric respiratory system reduce functional reserve and predispose these patients to respiratory decompensation and collapse in the perioperative period. In terms of physiology these include: immature ventilatory control; inefficient respiratory muscles; predisposition to small airway closure (due to reduced functional residual capacity and increased closing volume); and higher oxygen consumption due to the metabolic requirements of growth and temperature homeostasis (1). The use of increased inspired oxygen concentrations to mitigate these issues can potentially depress ventilatory effort and precipitate retinopathy and/ or bronchopulmonary dysplasia. Neonates exhibit a blunted 
response to hypercapnia and therefore are less able to mitigate against type 2 respiratory failure.

Regarding anatomical considerations, the trachea in infants is short and narrow, with immature and unstable cartilages. Endobronchial displacement, accidental extubation of the tracheal tube or obstruction to ventilation can therefore occur easily during surgical manipulation. The smaller cross-sectional area of the airway produces higher resistance to airflow (2) and any further reduction in diameter (e.g., mucosal oedema, stenosis of any part of airways including larynx or trachea, presence of blood clots or secretions and/or placement of an inappropriately small tracheal tube) is extremely poorly tolerated.

The accessory respiratory muscles are less effective and immature in younger children. The skeletal configuration of infants, with horizontally placed ribs, limiting the inspiratory increase in cross-sectional area of the thorax seen in adults (3).

\section{Unique characteristics of paediatric cardiovascular physiology:}

The transitional circulation, which persists for days to several weeks, can be extremely vulnerable to changes in pulmonary vascular resistance. Rises in pulmonary vascular resistance due to hypoxia, hypothermia, hypercarbia and acidosis may reopen the ductus arteriosus and foramen ovale and may regress the transitional circulation to a persistent foetal circulation (4). The neonatal myocardium operates at near maximal contractility because of a relatively high concentration of endogenous catecholamines and thyroid hormones released during late gestation and at birth $(5,6)$. The immature, poorly compliant neonatal myocardium has a lower capacity to increase cardiac output in the event of an increase in preload (7). Hence the newborn's heart is less able to compensate for the significant changes in loading conditions that can occur during anaesthesia and surgery (8). Depression of myocardial contractility caused by anaesthetic agents or other physiological derangement (e.g., hypoxia, hypovolaemia, arrhythmia, acidosis and electrolyte imbalance) may cause sudden catastrophic circulatory collapse $(9,10)$.

Performing airway surgery in paediatric patients with these physiological characteristics is therefore a challenging task, and would be impossible in many cases without the use of some form of extra-corporeal circulatory support. This support can be achieved by either conventional full cardiopulmonary bypass $(\mathrm{CPB})$ or extracorporeal membrane oxygenation (ECMO). What follows is an overview of the application of these techniques in our practice.

$\mathrm{CPB}$ is widely used in most of our tracheal surgeries. Most common surgeries include slide tracheoplasty for long segment tracheal stenosis and resection of trachea with endto-end anastomosis for shorter segmental lesions. Other surgery carried out under CPB include reconstruction of the trachea and/or bronchi including the carina for various tumours, repair following failed or complex tracheoesophageal fistula repair, and post-traumatic tracheal and bronchial reconstruction (e.g., following blunt-force trauma to the chest or following button battery ingestion).

\section{Role of CPB in long segment congenital tracheal stenosis (LSCTS)}

Management of LSCTS caused by the presence of complete cartilaginous tracheal rings has been revolutionised by the advent of the slide tracheoplasty technique (11). Since then, increasing numbers of slide tracheoplasties are being performed worldwide for this condition in children under CPB.

Clinical presentation with LSCTS in small babies is largely determined by the severity of airway stenosis. The majority of these children present with some form of respiratory distress; in our experience, at least $12 \%$ present with acute respiratory failure needing extra-corporeal support in the form of ECMO. An additional $20 \%$ of them will need invasive ventilation before arriving at a specialised centre for surgical repair. With this severity of disease, it is natural to expect these unstable children to require CPB for further surgery.

Quite often tracheal intubation involves use of an appropriately sized tube at, or just below the vocal cords, to facilitate maintenance of ventilation while these babies are transported to a surgical centre. CPB facilitates changing these tubes to appropriate sized tube at correct position as well as managing them after surgery in a stable manner.

In addition to pre-operative factors influencing the use of $\mathrm{CPB}$, there are other intraoperative considerations that make the use of CPB beneficial or essential. One key factor is that, particularly with LSCTS, the stenosis is often too severe to pass a tracheal tube through. In adult tracheal surgery, it is often possible to maintain a route for ventilation by intubating the distal trachea or a main bronchus; in severe LSCTS this is impossible, and extracorporeal circulation becomes the only way to maintain 
gas exchange during surgery.

Another factor is the length of the stenotic segment, including extension of complete rings to either of the bronchi. At surgery, extensive dissection is often required for adequate mobilisation of the airways. This includes release of subcarinal and paratracheal tissues; this enhanced mobility is essential for a secure and tensionfree anastomosis, while also allowing vascularity to be maintained. Adequate gas exchange needs to be maintained during these mobilisation maneuvers, and this would often be extremely difficult or impossible to achieve using standard ventilation. Use of $\mathrm{CPB}$ enables us to dissect, loop and retract the ascending aorta for the carinal and left main bronchus dissection, and the same for the right pulmonary artery and superior vena cava for right main bronchus dissection. While on CPB the tracheal tube may be removed and changed to an appropriately sized tube without any oxygenation compromise. At the end of reconstruction, this chosen tube is positioned at the correct depth under direct vision for postoperative care.

Finally, associated lesions are very common in this situation, in particular the left pulmonary artery sling. Correction of these lesions as well as intracardiac defects is facilitated greatly by the use of CPB (12).

\section{Role of CPB in complex tracheobronchial reconstructions following tracheo-esophageal fistula repair}

Complex airway pathologies are not uncommon in children. These include surgical failure following previous repair of tracheo-esophageal fistula and some form of injury to the airway following button battery ingestion; the latter can cause rapid and severe damage to the oesophagus and tracheobronchial tree.

Management of the complication of postoesophagectomy tracheo-bronchial-oesophageal fistula (PETEF) complication is uncertain and not standardised. The location of the oesophagogastric anastomosis next to the membranous wall of the trachea and mainstem bronchi and intimate relationship of the airway and proximal oesophagus predispose the airway to injury during an esophagectomy (13).

From various reported case series, fistulae with small defects and minimal mediastinal adhesions due to mediastinitis are accessed through cervical or cervicomediastinal approaches or posterolateral right thoracotomy. More extensive defects, following multiple reoperations, defects with frozen anatomy and complex abnormal vascular anatomy remain challenging to repair, and the optimal conditions provided by CPB via sternotomy may be required (14). In cases with complex abnormal vascular anatomy, use of $3 \mathrm{D}$ reconstruction of the images facilitates planning of the surgical approach. Under CPB, extremely vascular adhesions can be dealt with confidently, and the true extent of the defect safely defined. Estimating the true extent of the defect after extensive dissection helps in preventing failure of the repair requiring subsequent reintervention. Simultaneously such extensive defects can be repaired with autologous pedicled pericardial patch.

\section{Role of ECMO and CPB in tracheal and bronchial reconstruction after injury due to button battery ingestion and chest trauma}

A significant proportion of children referred to our unit (under the UK national tracheal service for complex airway surgery) present with complex airway injuries. ECMO is a valuable tool in stabilising such patients initially, as these patients often arrive in extremely fragile condition with a decompensated cardiorespiratory status. The choice of ECMO can be either veno-veno or veno-arterial depending on the clinical picture. Once stabilised, these children undergo an array of investigations on the airway, including contrast-enhanced computed tomography (CT) scan and bronchoscopy and bronchogram. Optical coherence tomography (OCT) in particular, is very valuable in showing the contrast quality of the tracheobronchial wall.

Children with unstable airways can potentially be at further risk at induction of anaesthesia (assuming ECMO has not been instituted preoperatively). Tracheal intubation can result in further trauma to the defect, and positive pressure ventilation can cause life-threatening tension pneumomediastinum. One strategy for managing this situation is to maintain spontaneous ventilation via a supraglottic airway device (SAD), such as a laryngeal mask airway (LMA). This can be used to maintain oxygenation until sternotomy is completed and CPB instituted (gentle positive pressure will be needed once the chest is open). This strategy clearly requires close communication and collaboration between surgeon and anaesthetist at all times.

In situations of caustic injury to the airways, additional debridement of the airway becomes an important step to prevent ongoing necrosis of the tissues while reconstruction 
(often using an autologous pericardial patch) is attempted. Use of CPB can further facilitate this step, in addition to repair of the esophagus at the same time via an anterior approach.

\section{Role of CPB in tracheal and carinal tumour resection}

Tumours, including both malignant and benign lesions can need further extra-corporeal support for surgery. As described above, tracheal tumours that extend beyond a short segment may need complex surgical reconstruction of the airway. Carinal tumours, especially carcinoid and proximal bronchial adenoids, where there are no resection margins to the carina for complete clearance, usually require CPB (15). Inflammatory myofibroblastic tumours are the commonest childhood airway tumour in our experience. Resection is by wide local excision with clear surgical margins. In such situations, the use of CPB can facilitate complete surgical cure in these children (16-18).

\section{A comparison of the merits of CPB versus ECMO}

Although CPB and ECMO have made complex airway lesions surgically correctable, there are significant deleterious effects to consider. Contact with the extracorporeal circuit activates an inflammatory response which, in combination with particulate emboli, multiple gaseous and/or lipoproteins generated due to disruption of the glycocalyx during CPB may all contribute to postoperative multiorgan dysfunction (19). The systemic inflammatory response is produced by proinflammatory mediators, activated leucocytes, vascular endothelial cells, and platelets. Coagulopathy caused due to factor depletion, use of heparin and haemodilution during $\mathrm{CPB}$ results in coagulopathy, postoperative bleeding requiring surgical reoperation, and increased transfusion requirements (20).

Several prospective studies have demonstrated a higher incidence of circulating TNF- $\alpha,(21,22)$. TNF- $\alpha$ is also a critical factor in initiating the cytokine cascade responsible for tissue ICAM-1 induction and subsequent neutrophil sequestration (23). In patients with comorbid conditions that are associated with postoperative renal dysfunction, $\mathrm{CPB}$ is associated with an increased risk of dialysisdependent renal failure (24).
$\mathrm{CPB}$ is associated with significant pulmonary cytokine production (IL-8), neutrophil sequestration, and alveolar macrophage activation in clinical studies (25). This results in significant increases in static and dynamic compliance of the respiratory system and lung and work of breathing (26). The incidence of overt stroke, following cardiac surgery, ranges from $1 \%$ to $6 \%$ while the incidence of neurocognitive dysfunction is as high as $60 \%$ at 1 week with reduction to $25 \%$ to $30 \%$ at 8 weeks and 12 months (27).

Several technical innovations have resulted in less intraoperative hemolysis, blood activation, and the circulation of emboli. These include: biocompatible plastics; in-line filters; membrane oxygenators ( $v s$. bubble oxygenators); and centrifugal blood pumps (vs. roller pumps) (28). Surface modification of circuits with heparin to mimic the native circulation and the use antifibrinolytics (e.g., aprotinin, tranexamic acid) have been shown to attenuate blood component activation, systemic inflammation, and organ dysfunction (29,30). Even with these developments, post-CPB inflammation and organ dysfunction are attenuated but not abolished (31).

There is some evidence that ECMO confers some advantages over $\mathrm{CPB}$ with regard to the inflammatory response. Firstly, the blood-air interface present in the venous reservoir in CPB is thought to be particularly important in activating the systemic inflammatory response. This is not present in the ECMO circuit. Similarly, haemodilution, which is known to contribute to coagulopathy and inflammatory activation, is less likely to occur during ECMO than CPB. Finally, the necessary use of protamine at the termination of $\mathrm{CPB}$ produces protamine-heparin complexes that are known to worsen the inflammatory response via complement activation (32). Despite these advantages of ECMO over CPB, there are several critical technical differences that make $\mathrm{CPB}$ a better strategy than ECMO during airway surgery. These are detailed in Table 1 .

\section{Conclusions}

Complex airway surgery has evolved well beyond routine sliding tracheoplasty in children. Use of extra-corporeal support have greatly facilitated procedures, both in stabilising these children pre-operatively (using ECMO) and conducting safe and effective surgical repair (using CPB). 
Table 1 Key differences between cardiopulmonary bypass as against ECMO

\begin{tabular}{lll}
\hline Factors & CPB & ECMO \\
\hline Capillary pressures & Low & High \\
Circulation & $\begin{array}{l}\text { Decompressed ventricles, making surgical } \\
\text { manipulation easier } \\
\text { Cannulae }\end{array}$ & $\begin{array}{l}\text { Circulation is often full - with less effective } \\
\text { decompression. Needs additional Vent }\end{array}$ \\
mobilisation at surgery and control of flows & Can be very temperamental \\
Strategy & $\begin{array}{l}\text { Dynamic bypass strategy with intermittent low flow } \\
\text { can be made safe with systemic cooling }\end{array}$ & $\begin{array}{l}\text { Lack of rapid systemic cooling means that safe } \\
\text { dynamic low flow strategies are not possible }\end{array}$ \\
\hline Bleeding during procedure & Retained under CPB using cardiotomy suckers & Lost from circulation
\end{tabular}

CPB, cardiopulmonary bypass; ECMO, extracorporeal membrane oxygenation.

\section{Acknowledgments}

Funding: None.

\section{Footnote}

Provenance and Peer Review: This article was commissioned by the Guest Editors (Andrea Dell'Amore and Nizar Asadi) for the series "Mechanical Extracorporeal CardioRespiratory Supports in General Thoracic Surgery" published in Current Challenges in Thoracic Surgery. The article has undergone external peer review.

Conflict of Interest: The authors have completed the ICMJE uniform disclosure form (available at http:// dx.doi.org/10.21037/ccts-21-9). The series "Mechanical Extracorporeal Cardio-Respiratory Supports in General Thoracic Surgery" was commissioned by the editorial office without any funding or sponsorship. Dr. Muthialu serves as an unpaid editorial board member of Current Challenges in Thoracic Surgery from Sep 2019 to Aug 2021. The authors have no other conflicts of interest to declare.

Ethical Statement: The authors are accountable for all aspects of the work in ensuring that questions related to the accuracy or integrity of any part of the work are appropriately investigated and resolved.

Open Access Statement: This is an Open Access article distributed in accordance with the Creative Commons Attribution-NonCommercial-NoDerivs 4.0 International License (CC BY-NC-ND 4.0), which permits the noncommercial replication and distribution of the article with the strict proviso that no changes or edits are made and the original work is properly cited (including links to both the formal publication through the relevant DOI and the license). See: https://creativecommons.org/licenses/by-nc-nd/4.0/.

\section{References}

1. Gonzalez LP, Pignaton W, Kusano PS, et al. Anaesthesiarelated mortality in pediatric patients: A systematic review. Clinics (Sao Paulo) 2012;67:381-7.

2. Stocks J, Godfrey S. Specific airway conductance in relation to postconceptional age during infancy. J Appl Physiol 1977;43:144-54.

3. Saikia D, Mahanta B. Cardiovascular and respiratory physiology in children. Indian J Anaesth 2019;63:690-7.

4. Sharma A, Ford A, Calvert J. Adaptation for life: A review of neonatal physiology. Anaesth Intensive Care Med 2010;12:85-90.

5. Breall JA, Rudolph AM, Heymann MA. Role of thyroid hormone in postnatal circulatory and metabolic adjustments. J Clin Invest 1984;73:1418-24.

6. Mahdavi V, Izumo S, Nadal-Ginard B. Developmental and hormonal regulation of sarcomeric myosin heavy chain gene family. Circ Res 1987;60:804-14.

7. Motoyama KE, Davis PJ. editors. Cardiovascular physiology in infants and children. Ch 3. Smith's Anesthesia for Infants and Children. 7th ed. Mosby: An Imprint of Elsevier, 2005.

8. AWHONN's Perinatal Nursing. 3rd ed. Philadelphia, PA: Lippincott Williams \& Wilkins, 2008:527-45.

9. Anderson PA, Glick KL, Manring A, et al. Developmental changes in cardiac contractility in fetal and postnatal sheep: In vitro and in vivo. Am J Physiol 1984;247:H371-9. 
10. Klopfenstein HS, Rudolph AM. Postnatal changes in the circulation and responses to volume loading in sheep. Circ Res 1978;42:839-45.

11. Tsang V, Murday A, Gilbe C, et al. Slide tracheoplasty for congenital funnel-shaped tracheal stenosis. Ann Thorac Surg 1989;48:632-5.

12. Ramaswamy M, Yeh YT, Varman R, et al. Staging of Surgical Procedures in Comorbid Congenital Tracheal Stenosis and Congenital Cardiovascular Disease. Ann Thorac Surg 2020;109:1889-96.

13. Bartels HE, Stein HJ, Siewert JR. Tracheobronchial lesions following oesophagectomy: prevalence, predisposing factors and outcome. Br J Surg 1998;85:403-6.

14. Balakrishnan A, Tapias L, Wright CD, et al. Surgical Management of Post Esophagectomy Tracheo-BronchialEsophageal Fistula. Ann Thorac Surg 2018;106:1640-6.

15. Horita K, Itoh T, Furukawa K, et al. Carinal reconstruction under veno-venous bypass using a percutaneous cardiopulmonary bypass system. Thorac Cardiovasc Surg 1996;44:46-9.

16. Kim CW, Kim DH, Son BS, et al. The Feasibility of Extracorporeal Membrane Oxygenation in the Variant Airway Problems. Ann Thorac Cardiovasc Surg 2015;21:517-22.

17. Nakamura H, Taniguchi Y, Miwa K, et al. Primary adenocarcinoma of the trachea resected using percutaneous cardiopulmonary support (PCPS). Ann Thorac Cardiovasc Surg 2007;13:338-40.

18. Jeon HK, So YK, Yang JH, et al. Extracorporeal oxygenation support for curative surgery in a patient with papillary thyroid carcinoma invading the trachea. J Laryngol Otol 2009;123:807-10

19. Butler J, Pillai R, Rocker GM, et al. Effect of cardiopulmonary bypass on systemic release of neutrophil elastase and tumour necrosis factor. J Thorac Cardiovasc Surg 1993;105:25-30.

20. Despotis GJ, Avidan MS, Hogue Jr CW. Mechanisms and attenuation of hemostatic activation during extracorporeal circulation. Ann Thorac Surg 2001;72:S1821-31.

21. Wan S, Izzat MB, Lee TW, et al. Avoiding cardiopulmonary bypass in multivessel CABG reduces

doi: $10.21037 /$ ccts-21-9

Cite this article as: Beeman A, Ramaswamy M, Robertson A, Ip J, Muthialu N. Airway surgery in children under extracorporeal circulatory support. Curr Chall Thorac Surg 2021. cytokine response and myocardial injury. Ann Thorac Surg 1999;68:52-6.

22. Brasil LA, Gomes WJ, Salomao R, et al. Inflammatory response after myocardial revascularization with or without cardiopulmonary bypass. Ann Thorac Surg 1998;66:56-9.

23. Frangogiannis NG, Lindsey ML, Michael LH, et al. Resident cardiac mast cells degranulate and release preformed TNF-alpha, initiating the cytokine cascade in experimental canine myocardial ischemia/reperfusion. Circulation 1998;98:699-710.

24. Yokoyama T, Baumgartner FJ, Gheissari A, et al. Offpump versus on-pump coronary bypass in high-risk subgroups. Ann Thorac Surg 2000;70:1546-50.

25. Kotani N, Hashimoto H, Sessler DI, et al. Neutrophil number and interleukin- 8 and elastase concentrations in bronchoalveolar lavage fluid correlate with decreased arterial oxygenation after cardiopulmonary bypass. Anesth Analg 2000;90:1046-51.

26. Roosens C, Heerman J, De Somer F, et al. Effects of off-pump coronary surgery on the mechanics of the respiratory system, lung, and chest wall: Comparison with extracorporeal circulation. Crit Care Med 2002;30:2430-7.

27. Taylor KM. Central nervous system effects of cardiopulmonary bypass. Ann Thorac Surg 1998;66:S20-4.

28. Cooley DA, Frazier OH. The past 50 years of cardiovascular surgery. Circulation 2000;102:IV87-93.

29. Mojcik CF, Levy JH. Aprotinin and the systemic inflammatory response after cardiopulmonary bypass. Ann Thorac Surg 2001;71:745-54.

30. Paparella D, Yau TM, Young E. Cardiopulmonary bypass induced inflammation: Pathophysiology and treatment. An update. Eur J Cardiothorac Surg 2002;21:232-44.

31. Menasché P. The systemic factor: The comparative roles of cardiopulmonary bypass and off-pump surgery in the genesis of patient injury during and following cardiac surgery. Ann Thorac Surg 2001;72:S2260-65.

32. Schaub C, Thomas O, Åkervall Fridh L, et al. Protamine dosage effects on complement activation and sonoclot coagulation analysis after cardiac surgery. Cardiovasc Syst 2013;1:4358. 